\title{
ХИМИЧЕСКИЙ СОСТАВ И ФАРМАКОЛОГИЧЕСКИЕ СВОЙСТВА РАСТЕНИЙ РОДА GLEDITSIA L. (ОБЗОР ЛИТЕРАТУРЫ)
}

\author{
(С Сальникова Н.А. ${ }^{1}$, Самотруева М.А. ${ }^{1}$, Коновалов Д.А. ${ }^{2}$ \\ ${ }^{1}$ Астраханский государственный медицинский университет (АГМУ) \\ Россия, 414000, Астраханская область, г. Астрахань, ул. Бакинская, 121 \\ ${ }^{2}$ Пятигорский медико-фармацевтический институт (ПМФИ) \\ Россия, 357532, Ставропольский край, г. Пятигорск, пр. Калинина, 11
}

\begin{abstract}
В статье проводится анализ мировой научной литературы по вопросу изученности видов рода Gleditsia L. (Гледичия), произрастающих практически на всех континентах, но особое внимание привлечено к видам Gleditsia caspia Desf. и Gleditsia tricanthos L. как основных представителей североамериканской флоры на территории Российской Федерации. Разные морфологические части растений рода Gleditsia L. содержат богатый химический состав, соотношение которого зависит от видовой принадлежности растения. В сырье G. sinensis обнаружены фенольные соединения и фенольные кислоты, флавоноиды, люпиновая кислота, эхиноцистовая кислота, тритерпеновые сапонины. G. caspica содержит тритерпеновые сапонины, монотерпеновые кислоты и стеролы, бисдесмозидные сапонины, флавононы. B G. delavayi обнаружены тритерпеновые сапонины. Галактоманнаны обнаружены в стручках G. macracantha и G. triacanthos. В сырье G. triacanthos обнаружены 8 флавоноидов, включая 6 флавоноидных гликозидов: виценин-II, люценин, изоориентин, ориентин, витексин, изовитексин вместе с двумя агликонами, а именно лютеолином и апигенином. Широкий спектр фармакологического действия растений рода Gleditsia L. подтвержден многолетним опытом китайской и корейской народной медицины, коренными жителями Северной Америки и современными научными данными. Разными авторами в условиях in vitro для сырья Gleditsia L. подтверждены спазмолитическая и цитотоксическая активность, противовоспалительное, антимутагенное и антимикробное действие.
\end{abstract}

Ключевые слова: Gleditsia L.; флавоноиды; тритерпеновые сапонины; галактоманнаны; фармакологические свойства.

Сальникова Наталья Алексеевна - канд. мед. наук, доцент, доцент кафедры фармакогнозии, фармацевтической технологии и биотехнологии, АГМУ, г. Астрахань. ORCID iD: 0000-0003-2783-4059. E-mail: natalya-salnikova-81@mail.ru (aвтор, ответственный за переписку)

Самотруева Марина Александровна - д-р мед. наук, доцент, зав. кафедрой фармакогнозии, фармацевтической технологии и биотехнологии, АГМУ, г. Астрахань. ORCID iD: 0000-0001-5336-4455. E-mail: ms1506@mail.ru

Коновалов Дмитрий Алексеевич - д-р фарм. наук, профессор, зав. кафедрой кафедрой фармакогнозии, ботаники и технологии фитопрепаратов, ПМФИ, г. Пятигорск. ORCID iD: 0000-0002-0960-6127. E-mail: $\underline{\text { d.a.konovalov@pmedpharm.ru }}$

\section{ЭКОЛОГО-БОТАНИЧЕСКАЯ \\ ХАРАКТЕРИСТИКА РОДА ГЛЕДИЧИЯ GLEDITSIA L.}

Род древесных растений Гледичия Gleditsia L. относится к североамериканской флоре, занимает следующее систематическое положение: отдел Magnoliophyta, класс Magnoliopsida, порядок Fabales, семейство Fabaceae. Насчитывает порядка 10 видов, произрастающих в Центральной и Юго-Восточной Азии, Северной и Южной Америке, Северной Африке: гледичия водяная G. aquatic Marshall, гледичия аморфная G. amorphoides, гледичия австралийская G. australis, гледичия деловая G. delavayi, гледичия агрессивная G. ferox, гледичия каспийская G. caspia Desf., гледичия трехколючковая G. tricanthos L., гледичия японская G. japonica Loddiges Cat. ex Loudon, гледичия китайская (субтаксон) G. macracantha Desf., гледичия китайская G. sinensis Lam. На территории Российской Федерации, согласно ботанической сводке С.К. Черепанова, произрастает два вида рода: Gleditsia caspia Desf. (G. horrida) и Gleditsia tricanthos L. [9].

Gleditsia L. представляет собой листопадные деревья с крупными колючками на ветках, произрастает на периодически затапливаемых иллювиальных, дренированных почвах, выдерживает небольшое засоление почвенного слоя, отличается засухоустойчивостью и морозоустойчивостью, продолжительность жизни составляет порядка 120 лет [7]. Коренное население Америки гледичию называли Honey locust за сладкий вкус мякоти плодов, которая использовалась в пищу и производстве алкогольных и безалкогольных напитков [52]. Промышленный интерес к древесине гледичии связан с декоративностью и высокой способностью поддаваться полировке и вощению, используется для изготовления шпал, столбов, так как долго не поддается гниению в почве [2].

Gleditsia caspia Desf. представляет собой деревья высотой до $13 \mathrm{~m}$, с шаровидной кроной и стволом до 40 см в диаметре, побеги желтоватозеленого цвета. Колючки черные простые, реже 
ветвистые. Листья просто перистосложные, листочки яйцевидные длиной 2-4 см. Цветочные кисти 10-12 см длиной. Бобы широкие, прямые [2].

Gleditsia tricanthos L. - деревья высотой до 45 м, с ажурной кроной. Стебель темно-бурого цвета, морщинистый. На стволе и ветвях расположены острые колючки длиной до 10 см. Листья просто парноперистосложные с 8-15 парами продолговато-ланцетными листочками. Соцветие узко кистевидное, цветки на коротких ножках. Бобы удлиненно-ланцетные длиной до 45 см и шириной до 3 см, изогнутые и вдоль спирально закрученные, кожистые, темнокоричневые, со сладковатой мякотью. Семена удлиненно эллиптические, сплюснутые, коричневые, блестящие, длиной до 10 мм [7, 59].

\section{ФИТОХИМИЧЕСКИЙ СОСТАВ РАСТЕНИЙ}

Химический состав различных частей растений рода Gleditsia L. привлекал внимание ученых многих стран мира на протяжении последних 50 лет.

В сырье G. sinensis обнаружены полифенольные соединения и фенольные кислоты [34, 63], флавоноиды [50], люпиновая кислота [32], эхиноцистовая кислота [60], тритерпеновые сапонины $[13,31,62]$. G. caspica содержит тритерпеновые сапонины, монотерпеновые кислоты и стеролы [39, 55], бисдесмозидные сапонины [11, 40], флавононы [42]. B G. delavayi обнаружены тритерпеновые сапонины [46].

A. Diego с соавторами в 2002 году получили водное извлечение эндосперма из семян G. triacanthos, разделив его на две фракции с помощью метода анионообменной хроматографии и методами 1D и 2D ЯMР-спектроскопии. Фракция, которая элюируется водой, представляет собой арабинан с $(1 \longrightarrow 5) \alpha-\mathrm{L}-$ связями и разветвлениями, главным образом, на С-2, сопровождаемые равными количествами галактоманнанового олигосахарида с низким содержанием галактозы и небольшой долей $\beta-(1 \rightarrow 4)$ галактана. Фракция, которая элюируется спиртом, представляет собой арабинан и галактоманнан с более высоким содержанием галактозы, галактана и белка [18].

Впервые из семян $\mathrm{G}$. triacanthos f. Inermis А.В. Егоровым, Н.М. Местечкиной и В.Д. Щербухиным был выделен галактоманнан $(15,4 \%)$ с высокой оптической плотностью [23]. Галактоманнаны обнаружены также в стручках G. macracantha и G. triacanthos $[12,38,53,56]$.

L.S. Sciarini с соавторами исследовали семена G. triacanthos в качестве источника галактоманнана на количественное соотношение манноза: галактоза (Man:Gal) и выяснили, что оно зависит от методов выделения и очистки продукта. В данном исследовании использовали три способы выделения: обработка кипятком (M1), концентрированным раствором $\mathrm{NaOH}$ (M2) и набухание в воде с последующим ручным удалением эндосперма (М3). Функциональные свойства гидроколлоидов, полученные тремя способами выделения, сравнивались с ксантановой и гуаровой камедью. Продукт M1 имел самый низкий выход, но показал высокую водопоглощающую способность и растворимость, высокую эмульгирующую и пенообразующую способность и придал высокую стабильность дисперсиям (пенам и эмульсиям) [51].

В 2004 году российскими учеными А.В. Егоровым, Н.М. Местечкиной и В.Д. Щербухиным из семян G. ferox, интродуцированной в России, был выделен галактоманнан молекулярной массой 1660 кДа и с выходом 18,9\%. Хроматографическими и спектральными методами установлено, что галактоманнан состоит из D-маннопиранозы и D-галактопиранозы (молекулярное соотношение 2,54:1,0), вероятность встречаемости в цепи молекулы маннобиозных звеньев составила для незамещенных звеньев 0,37, для однозамещенных - 0,47, для двузамещенных - 0,16 [5, 24].

Д.Н. Оленников и А.В. Рохин в одной из работ методом горячей водной экстракции из семян Gleditsia sinensis L. выделили галактоманнан (выход составил 4,5\% от массы семян) с молекулярной массой 1230 кДа. Полученный галактоманнан состоял из остатков маннозы и галактозы в молярном соотношении 2,69:1,0. С помощью 13С-ЯМР-спектроскопии установлено, что в данном галактоманнане встречаются следующие участки звеньев: Ман-Ман, (Гал)Ман-Ман и Ман-Ман(Гал) (в сумме), а также (Гал)Ман-Ман(Гал), соотношение которых составляет 0,23:0,47:0,30 [8].

Y. Liu с соавторами в 2016 году исследовали физико-химические свойства камеди семян Gleditsia sinensis (GSG) и Gleditsia microphylla (GMG), которую очищали и осаждали с использованием различных концентраций этанола и изопропанола. Ученые провели осаждение галактоманнана из GSG и GMG в 33,3\% этаноле, что составило $81,7 \%$ и $82,5 \%$ соответственно, а в $28,8 \%$ изопропаноле - $81,3 \%$ и $82,9 \%$ соответственно. Таким образом, более высокое соотношение полисахаридов манноза/галактоза и более высокая молекулярная масса были получены при более низкой концентрации спиртов [36].

Фенольные соединения обнаружены в сырье G. triacanthos [26] учеными из Египта, которые идентифицировали в нем 8 флавоноидов, включая 6 флавоноидных гликозидов: виценин-II, 
люценин, изоориентин, ориентин, витексин, изовитексин вместе с двумя агликонами, а именно лютеолином и апигенином [54].

Коллектив ученых во главе с Р.К. Рахманбердиевым изолировали и изучили водорастворимые полисахариды из семян восьми видов гледичии. Галактоманнаны проявили различную вязкость, специфические вращения молекул и соотношение галактозы и маннозы. Изучение их химических превращений и ИКспектральных данных показало, что моносахаридные остатки являются пиранозами, связанными $\beta$-1-4-гликозидными связями и имеющими во втором компоненте D-галактозу с $\alpha$-конфигурацией гликозидного центра и наиболее вероятной конформацией стула пиранозного кольца [43].

Р.К. Рахманбердиевой, Д.А. Рахимовым, М.Р. Мирзаевой проведена работа по всестороннему изучению химической структуры и свойств галактоманнана из оболочки семян G. texana. Кислотный гидролиз олигосахаридов и продуктов их восстановления показал, что олигосахарид А является маннобиозой, В - галактозилманнозой, C - маннотриозой, D - маннотетраозой. Полученный галактоманнан из семян G. teхаnа отличается от других видов гледичии расположением мономеров в цепи, молекулярной массой и другими характеристиками. Также этими авторами тщательна изучена структура галактоманнана из семян G. масrаcantha методом метилирования, периодатного окисления и частичного кислотного гидролиза. Основная полигликозидная цепь данного полисахарида состоит из $\beta-1 \longrightarrow 4$-связанных маннопиранозных звеньев, где манноза замещена в 6-положении одиночными $\alpha$-D-галактопиранозными звеньями [44, 45].

Детально Р.К. Рахманбердиевой, М. Талиповой и Ф. Газизовым исследован углеводный и липидный состав семян G. triacanthos L., культивируемой в Узбекистане, из которых выделены водорастворимые полисахариды, пектиновые вещества, гемицеллюлоза, а также определен жирнокислотный состав нейтральных, глико- и фосфолипидов [48].

В 2003 году А.В. Егоровым, Н.М. Местечкиной и В.Д. Щербухиным была изучена первичная структура галактоманнана семян G. triacanthos с помощью современных хроматографических и спектроскопических методов. Макромолекула с молекулярной массой 660 кДа имеет цепь, построенную из 1,4-Р-Бманнопиранозных остатков, $41 \%$ которых замещен по С-6 единичными остатками a-D-галактопиранозы. В цепи галактоманнана, вероятность встречаемости маннобиозных зве- ньев составляет для звена Ман-Ман 0,16, для Гал (Ман-Ман) и (Ман-Ман)Гал по 0,50 [4].

М.А. Дученко с соавторами исследовали аминокислотный и минеральный состав листьев и створок плодов G. triacanthos L. и обнаружили 16 аминокислот, в том числе 7 незаменимых. Доминирующими аминокислотами оказались: аспарагиновая, глутаминовая кислоты, глицин, аланин, лейцин, серин и триптофан. Также отмечено высокое содержание кальция, калия, кремния и магния в сырье G. triacanthos L. [21].

М.А. Дученко, В.М. Ковалев и С.В. Романова определили параметры стандартизации сухого экстракта из листьев G. triacanthos L., ими предложены методики качественного и количественного анализа флавоноидов (не менее 5,0\%) и фенольных соединений (не менее 9,0\%). Полученные результаты исследований авторы использовали при разработке методики контроля качества «Гледичии листьев экстракт сухой» [3].

М.А. Дученко в 2014 году проведены исследования полисахаридов листьев G. triacanthos L. Гравиметрическими методами определено количественное содержание водорастворимых полисахаридов, пектиновых веществ, гемицеллюлоз А и Б. Методом бумажной хроматографии исследован мономерный состав полисахаридов. В водорастворимом полисахаридном комплексе обнаружено 55,25\% основных и 20,83\% кислых моносахаридов. Пектиновые вещества состояли из 27,97\% основных и $10,02 \%$ кислых моносахаридов [19].

В работе J.-X. Jiang с соавторами приводится характеристика по структурным и термическим свойствам галактоманнанов из семян трех видов Gleditsia, а именно G. sinensis, G. microphylla и G. melanacantha. Современными хроматографическими и спектроскопическими методами авторы показали, что соотношение Ман:Гал в молекуле галактоманнанов гледичий составляло $3,25,3,31$ и 2,30 соответственно [28].

Японскими учеными во главе с Yui Harauchi в 2017 году из семян G. japonica были выделены три ранее не описанных изогуаниновых гликозида с $\mathrm{N}_{3}$-пренильной группой, обозначенных как $\mathrm{C}_{21} \mathrm{H}_{32} \mathrm{~N}_{5} \mathrm{O}_{10} \quad$ (Locustoside $\mathrm{B}$ ), $\mathrm{C}_{21} \mathrm{H}_{32} \mathrm{~N}_{5} \mathrm{O}_{11}$ (Saikachinoside B) и $\mathrm{C}_{22} \mathrm{H}_{34} \mathrm{~N}_{5} \mathrm{O}_{12}$ (Saikachinoside C), вместе с двумя известными соединениями, а именно с 7- $\beta$-d-глюкопиранозил-3-(3-метил-2бутенил)-изогуанин (Locustoside A) и 7- $\beta$-dглюкопиранозил-3-(Z)-4-гидрокси-3-метил-2бутенил изогуанин (Saikachinoside A). Их структуры были определены на основе спектроскопического и рентгеноструктурного анализа; проведена оценка ингибирующей активности в отношении кислой фосфатазы как маркера лизосомальных ферментов [27]. 
Группой ученых из Республики Узбекистан в 2019 году проводилась работа по выделению галактоманнанов из семян растений Sophora japonica и Gleditsia triacanthos и изучение их физико-химических свойств. Определены количественные характеристики содержания галактоманнанов и соотношение Ман:Гал в молекуле галактоманнана, проведен ферментативный гидролиз выделенных полисахаридов и изучен характер изменения моносахаридного состава в процессе гидролиза. Вязкость негидролизованного и гидролизованного галактоманнанов равна 4,85 дл/г и 3,80 дл/г соответственно. Авторы установили, что увеличение продолжительности ферментативного гидролиза приводит к образованию полиманнана с малым содержанием галактозных единиц [1].

\section{ПРИМЕНЕНИЕ ГЛЕДИЧИИ В НАРОДНОЙ МЕДИЦИНЕ}

Критический анализ мировой литературы выявил наиболее приоритетные направления применения видов рода Gleditsia L. в медицинской практике, их сырье используют в качестве противовоспалительных, противоопухолевых, антимикробных, противогрибковых, противовирусных, гемостатических, противоаллергических, муколитических, тонизирующих средств [30].

Растения рода Gleditsia на протяжении последних 2000 лет широко используются в традиционной медицине Восточной Азии и Китая для лечения воспалительных процессов кожного покрова (фурункулы, сыпь, чесотка) и астматического кашля. Согласно «Compendium of Materia Medica», семена Gleditsia использовались при лечении диареи, дизентерии, отеков, а колючки растений - при лечении золотухи, острого мастита. В древнекитайской медицинской книге «Bencaojing Jizhu» имеется запись о применении растений при лечении чумы и экземы [10, 15, 22, 37].

В фармакопее Китайской Народной Республики 2010 года издания [15] G. sinensis относится к официальным растениям благодаря своему широкому спектру фармакологического действия и применяется для детоксикации и как противопаразитарное средство, а также для лечения язвы, сепсиса, чесотки и болезни Хансена.

В корейской народной медицине колючки G. sinensis широко используются для лечения карбункула, отеков, нагноений, чесотки и кожных заболеваний [57], а зрелые стручки и плоды в основном используются для лечения апоплексии яичников, кашля, астмы [10]; сухие плоды G. japonica используются в качестве мочегонного и отхаркивающего средства [29].
Жители Северной Америки надземную часть G. triacanthos применяли в качестве обезболивающего, антисептического, противоопухолевого средства, отдельно стручки растения для лечения кори, а кору дерева - для лечения коклюша, кори, оспы и диспепсии $[22,30]$.

В Республике Болгария местное население использует стручки и листья гледичии трехколючковой как слабительное средство [6].

\section{ФАРМАКОЛОГИЧЕСКИЕ СВОЙСТВА РАСТЕНИЙ РОДА GLEDITSIA L.}

В комплексных исследованиях М.А. Дученко, О.В. Демешко и В.Н. Ковалева листья и плоды G. triacanthos проявляли спазмолитическую активность в отношении гладкой мускулатуры кишечника и бронхов, гипертензивную активность за счет содержания в них алкалоида триакантина, слабительное действие за счет антрагликозидов из перикарпа растения. Авторами в статье показано, что концентрация биологически активных соединений в листьях G. triacanthos не подвержено значительным колебаниям в зависимости от сезона года и варьируют в небольшом диапазоне: флавоноиды 2,75 - 2,23\%; гидроксикоричные кислоты 1,80 1,77\%; фенольные соединения 4,91 - 3,36\% [20].

Р.К. Рахманбердиева с группой ученых изучили гипохолестеринемическую и гипогликемическую активность галактоманнана, выделенного из оболочек семян G. macracantha. В данном эксперименте с интактными крысами он значительно предупреждал развитие гипергликемии и сахарного диабета при одновременном применении с аллоксаном [47].

L.M.C. Chow с соавторами в 2002 году экспериментально доказали цитотоксическую активность экстракта плодов G. sinensis L. (GSE) на четырех линиях раковых клеток опухоли (рак молочной железы MCF-7, MDA-MB231, гепатобластома HepG2 и плоскоклеточная карцинома пищевода линии SLMT-1) с помощью MTTтеста, реакции свободного роста клеток, электрофоретического расщепления ДНК и апоптоза. Среднее значение минимально допустимой концентрации варьировало от 16 до 20 мкг/мл GSE. Используемые тесты и анализы показали, что все четыре линии опухолевых клеток постепенно теряют свой регенерационный потенциал после лечения GSE в зависимости от дозы и времени воздействия [16].

Изучена противолейкозная активность сапонинов, выделенных из экстракта плодов G. sinensis, на линиях раковых клеток и клетках костного мозга, полученных от пациентов с хроническим миелолейкозом (ХМЛ) и острым миелолейкозом (ОМЛ). В исследовании приме- 
нялись методы МТС-анализа, метод ДНКэлектрофореза, ПЦР-РТ и проточной цитометрии. Средняя концентрация для ингибирования роста $50 \%$ раковых клеток (MTS50) составила $18 \pm 1,6$ мкг/мл для линии клеток К562 ХМЛ и $12 \pm 1,3$ мкг/мл для линии клеток HL-60 ОМЛ. При инкубации лейкозных клеток с экстрактом G. sinensis наблюдалось расщепление ДНК раковых клеток, что подтверждено проточным цитометрическим анализом. Таким образом, экстракт гледичии может быть потенциально использован в качестве химиотерапевтического препарата для лечения больных острым и хроническим миелолейкозом [14].

Ученые из Саудовской Аравии в 2014 году в своих исследованиях изучали водноэтанольные экстракты листьев G. triacanthos, которые проявляли доказанную цитотоксическую активность в отношении раковых линий клеток печени (концентрация полумаксимального ингибирования $\mathrm{IC}_{50}=1,68$ мкг), молочной железы $\left(\mathrm{IC}_{50}=0,74\right.$ мкг), шейки матки (IC50 = 1,28 мкг), гортани $(\mathrm{IC} 50=0,67$ мкг) и толстой кишки $\left(\mathrm{IC}_{50}=2,50\right.$ мкг) [41].

Wan-Hua Li c соавторами из колючек

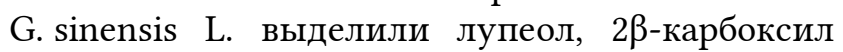
1,33-гидроксил-(1)-20(29)-ен-28-овую кислоту (2), вместе с пятью известными производными лупановой кислоты (2-6), чьи структуры были выяснены на основе методов 1D и 2D ЯМР. Все эти известные соединения были впервые выделены из растений рода Гледичия. Новое соединение 1 в исследованиях проявило достаточно сильную анти-ВИЧ активность [58].

В 2005 году J.C. Lim и соавторами проведены исследования по антимутагенной активности экстракта, полученного из колючек G. sinensis. Впервые ученые смогли выделить из экстракта один тритерпеноид и четыре стероида с молекулярными формулами: $\mathrm{C}_{30} \mathrm{H}_{48} \mathrm{O}(1), \mathrm{C}_{29} \mathrm{H}_{46} \mathrm{O}_{2}$ (2), $\mathrm{C}_{29} \mathrm{H}_{48} \mathrm{O}_{2}$ (3), $\mathrm{C}_{29} \mathrm{H}_{48} \mathrm{O}$ (4) и $\mathrm{C}_{29} \mathrm{H}_{50} \mathrm{O}$ (5). Наиболее активным антимутагеном оказался $\mathrm{C}_{29} \mathrm{H}_{48} \mathrm{O}$, который показал $51,2 \%$ и $64,2 \%$ снижения коэффициента индукции против мутагенов MNNG и $\mathrm{NQO}$, соответственно, в SOS хромотесте [35].

Chao Liu c коллегами в 2016 году провели исследование химического состава плодов G. sinensis и идентифицировали новые тритерпеновые сапонины с помощью одно- и двухмерного ядерного магнитного резонанса. Ученые впервые в условиях in vitro оценивали антипролиферативную активность этих соединений на клеточных линиях рака MCF-7 и Нер-G2, значения $\mathrm{IC}_{50}$ которых для двух линий клеток составили 9,5 и 11,6 мкм соответственно [13].

Jinqian Yu c соавторами из этанольного экстракта плодов G. sinensis выделили один новый тритерпеноидный сапонин (1), а также шесть известных (2-7) и доказали их цитотоксическую активность в отношении клеток рака молочной железы человека MCF-7 in vitro методом MTT. Результаты показали умеренную активность для соединений 1-6 со значениями $\mathrm{IC}_{50}$ 18,43 мкM, 30,47 мкM, 18,46 мкM, 10,02 мкM, 30,76 мкМ и 17,32 мкМ соответственно. Кроме того, соединения 1, 3, 4 и 6 индуцировали апоптоз в клетках MCF-7, причем 1 и 6 вызывали поздний апоптоз клеток MCF-7, в то время как 3 и 4 действовали противоположно [31].

Ehab A. Ragab в 2015 году провел фитохимическое исследование плодов G. aquatica и идентифицировал два новых бисдесмозидных тритерпеноидных сапонина - акватикасапонин А и акватикасапонин В, ацилированных двумя или одной монотерпеновой кислотами, и одного акватицина С и провели оценку антимикробной активности обнаруженных соединений. Акватикасапонин А проявил наибольшую активность против Syncephalastrum racemosum с минимально допустимой концентрацией в 9,2 мкM, акватикасапонин B - против Escherichia coli с минимально допустимой концентрацией в 67,3 мкM. Выделенные соединения также проявляли цитотоксическую активность в отношении клеточных линий рака молочной железы человека (MCF-7) и рака толстой кишки человека (НCT116) со значениями IC50 от 0,5 до 1,0 мкM. Установлено, что акватикасапонин А является наиболее активным в отношении клеточной линии рака толстой кишки со значением $\mathrm{IC}_{50}=$ 0,5 мкM [25].

Антимикробную активность этанольного экстракта колючек G. sinensis в отношении Bacillus subtilis и Xanthomonas vesicatoria исследовали Ligang Zhou с соавторами в 2007 году, при этом значения диаметра зон задержки роста (ДЗЗР) микроорганизмов составили 9,5 и 9,2 мм по сравнению со стрептомицином $(21,5$ и 13,8 мм соответственно). Неочищенный этанольный экстракт G. sinensis последовательно разводили растворителями повышенной полярности. Полученные фракции дополнительно разделили на колонке хроматографа, обнаружив этиловый галлат (1), кофейную кислоту (7) и пять флавоноидов: дигидрокемпферол (2), эриодиктиол (3), кверцетин (4), 3,3',5',5,7пентагидрофлавонол (5) и эпикатехин (6). Соединения 4, 5 и 7 проявили умеренное ингибирующее действие в отношении всех тестируемых видов бактерий, соединение 7 проявило наименьшую минимальную подавляющую концентрацию, равную 0,125 мг×мл $^{-1}$. Соединения 1 и 2 проявили слабую ингибирующую ак-

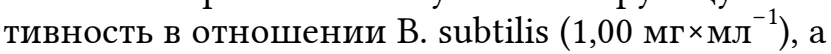
соединения 3 и 6 показали незначительную активность в отношении двух бактерий. Среди 
всех изученных фракций этанольного извлечения фракция ацетидина проявляла наиболее значительное ингибирующее действие на Bacillus subtilis и Xanthomonas vesicatoria (ДЗ3Р составил 14,5 и 11,3 мм соответственно), а минимальная ингибирующая концентрация (МИК) составила 1,25 и 5 мг/мл соответственно [33]. Также учеными протестированы два гликозида эллаговой кислоты (соединение 59 - 3-Ометилэллаговая кислота-4'-(5"-ацетил-)- $\alpha$ L-арабинофуранозид; соединение 60 - 3-Ометилэллаговая кислота-4'-O- $\alpha-\mathrm{L}-$ рамнопиранозид из этилацетатной фракции этанольного извлечения колючек G. sinensis в отношении возбудителя фитозаболеваний грибка Magnaporthe grisea. В результате соединения 59 и 60 показали умеренную ингибирующую активность при значениях IC50 13,56 и 16,14 мкг/мл соответственно [34].

Y. Dai с коллегами в 2002 году изучили противовоспалительное и антиаллергическое действие $70 \%$ этанольного извлечения из плодов G. sinensis в условиях in vivo. Извлечение (дозировка 200, 500, 1000 мг/кг) дозозависимо ингибировало системный анафилактический шок, индуцированный соединением 48/80 у мышей, и кожные реакции, индуцированные гистамином или серотонином у крыс. Также в исследованиях показано значительное ингибирование отека задней лапы у крыс и отека уха у мышей, вызванного каррагинином и кротоновым маслом соответственно. Данные результаты показывают, что этанольное извлечение из плодов G. sinensis обладает противоаллергической и противовоспалительной активностью, которые могут быть опосредованы снижением высвобождения медиаторов, таких как гистамин из тучных клеток и ослаблением воспалительного действия этих медиаторов [17].

Группа ученых в 2015 году провела исследование по оценке анальгетического действия метанольного извлечения плодов G. triacanthos и его сапонинсодержащей фракции. Периферийную обезболивающую активность извлечения оценивали с помощью модели кислотноиндуцированного болевого синдрома у мышей (уксусная кислота в дозах 140, 280 и 560 мг/кг) и крыс (формалин в дозах 100, 200 и 400 мг/кг). Центральную анальгетическую активность оценивали с использованием метода горячей пластины у крыс (100, 200 и 400 мг/кг). Результаты показали, что шесть групп мышей, получавших метанольное извлечение плодов G. triacanthos и сапонинсодержащую фракцию (ID50 268,2 и 161,2 мг/кг соответственно), меньше реагировали на болевое воздействие, по сравнению с группой, получавшей стандартный препарат индометацин (14 мг/кг). Сапонинсодержащая фракция в дозах 280 и 560 мг/кг показала 64,94 и $70,78 \%$ защиты соответственно, что более чем в два раза выше защиты, вызванной индометацином (31,82\%). В формалиновом тесте метанольное извлечение плодов G. triacanthos и сапонинсодержащая фракция (значения ID50 287,6 и 283,4 мг/кг для фазы I, а также 295,1 и 290,4 мг/кг для фазы II соответственно) при 400 мг/кг показали значительное ингибирование в обеих фазах (фаза I 18,86 и 52,57\%; фаза II 39,36 и $44,29 \%$ ) по отношению к 10 мг/кг индометацина (56,0 и 32,29\%). Извлечение и его фракция вызывали значительную задержку ответов на модели с горячей плитой (значения ID50 155,4 и 200,6 мг/кг соответственно) по сравнению с таковой для индометацина $10 \mathrm{Mr} /$ кг через 30, 60 и 120 минут [49].

Ученые Мичиганского государственного университета в 2015 году провели очистку экстрактов цветков G. triacanthos гексаном, этилацетатом и метанолом, что позволило получить три новых сложных эфира бетулиновой кислоты (1-3), один новый сложный эфир линалоолкарбоновой кислоты (4), терпеноиды (5-7) и полифенолы (8-11). Полученные компоненты тестировали на противовоспалительную и антиоксидантную активность в отношении ферментов циклооксигеназы (COX-1 и СОХ-2) и перекисного окисления липидов (ПОЛ) соответственно. Соединения 1-7 при 25 мкг/мл проявляли противовоспалительную активность, о чем свидетельствует ингибирование ферментов СОХ-1 и COX-2 в диапазоне 40-50\% и $33-37 \%$ соответственно. Противовоспалительная активность полученных экстрактов в дозе 25 мкг/мл превосходила аспирин и была сопоставима с другими безрецептурными нестероидными противовоспалительными препаратами (НПВП) напроксеном и ибупрофеном [61].

Таким образом, на основании анализа литературных источников, посвященных химическому и фармакологическому изучению видов рода Gleditsia L., были сделаны следующие выводы:

- растения рода Gleditsia L. в качестве основных биологически активных веществ, в зависимости от морфологической группы сырья содержат тритерпеновые сапонины, флавоноиды, фенольные соединения, галактоманнаны, алкалоиды, аминокислоты;

- доклинические и клинические исследования, проведенные учеными различных стран, позволили выявить широкий спектр фармакологического действия сырья видов рода Gleditsia L.

Исходя из вышеизложенного, актуальным является дальнейшее фитохимическое и фарма- 
кологическое изучение видов рода Gleditsia L., произрастающих на территории Прикаспийской низменности, как перспективных источников для получения новых эффективных лекарственных средств.

\section{КОНФЛИКТ ИНТЕРЕСОВ}

Авторы декларируют отсутствие явных и потенциальных конфликтов интересов, связанных с публикацией настоящей статьи.

\section{ИСТОЧНИКИ ФИНАНСИРОВАНИЯ} ния.

Авторы заявляют об отсутствии финансирова-

\section{ЛИTЕРАTУPA/REFERENCES}

1. Азимова Л.Б., Нормахаматов Н.С., Хайтметова С.Б., Мухитдинов Б.И., Амонова Д.М., Филатова А.В., Халилова Г.А., Киргизбаев Х.Х. и др. Выделение и изучение физико-химических свойств галактоманнанов из растительного сырья. Химия растительного сырья. 2019; 2:35-41 [Azimova L.B., Normahamatov N.S., Khaitmetova S.B., Mukhitdinov B.I., Amonova D.M., Filatova A.V., Khalilova G.A., Kirgizbaev H.H., Turaev A.S. Isolation and study of physical chemical properties of galactomannans from plant raw materials. Khimija Rastitel'nogo Syr'ja. 2019; 2:35-41 (in Russ.)] DOI: $\underline{10.14258 / \text { jcprm. } 2019024491}$

2. Деревья и кустарники СССР. Дикорастущие, культивируемые и перспективные для интродукuии. Том IV. Москва-Ленинград : Издательство Академии наук СССР, 1958. 973 с. [Trees and shrubs of the USSR. Wild, cultivated and promising for introduction. Vol.IV. Moscow-Leningrad: Publishing house of USSR Academy of Sciences; 1958. 973 p. (in Russ.)]

3. Дученко М.А., Ковалев В.М., Романова С.В. До питання стандартизації сухого екстракту листя гледичії звичайної. Запорожский медицинский журнал. 2012; 4-73:099-100 [Duchenko M.A., Kovalev V.M., Romanova S.V. To the question of standardization of the dry extract of the leaves of Gleditsia ordinary. Zaporozhye medical journal. 2012; 4-73:099100 (in Russ.)]

4. Егоров А.В., Местечкина Н.М., Щербухин В.Д. Установление первичной и тонкой структуры галактоманнана семян Gleditsia triacanthos f. inermis L. Прикладная биохимия и микробиология. 2003; 39(4):398-402 [Egorov A.V., Mestechkina N.M., Shcherbukhin V.D. Determination of the Primary and Fine Structures of a Galactomannan from the Seed of Gleditsia triacanthos f. inermis L. Applied biochemistry and Microbiology. 2003; 39(4):398-402]

5. Егоров А.В., Местечкина Н.М., Щербухин В.Д. Состав и структура макромолекулы галактоманнана семян Gleditsia ferox. Прикладная биохимия $и$ микробиология. 2004; 40:370-375 [Egorov A.V., Mestechkina N.M., Shcherbukhin V.D. Composition and structure of galactomannan macromolecule of Gleditsia ferox seeds. Applied biochemistry and Microbiology. 2004; 40:314-3018]
6. Кароматов И.Д., Джумаев К.Ш., Собиров Ш.Х. Медицинское значение Gleditsia triacanthos L. Биология и интегративная медицина. 2016; 1:156160 [Karomatov I.D., Dzhumaev K.SH., Sobirov Sh.Kh. Medical importance gleditsia triacanthos L. Biology and integrative medicine. 2016; 1:156-160 (in Russ.)]

7. Корниенко В.О., Калаев В.Н. Экологоморфологические и биомеханические особенности Gleditsia triacanthos в условиях антропогенного загрязнения города Донецка. Вестник ВГУ. Серия: химия, биология, фармация. 2018; 2:143-151 [Kornienko V.O., Kalaev V.N. Ecologicalmorphological and biomechanical features of Gleditsia triacanthos in the conditions of anthropogenic pollution of the city of Donetsk. Proceeding of Voronezh State University. Series: Chemistry. Biology. Pharmacy. 2018; 2:143-151 (in Russ.)]

8. Оленников Д.Н., Рохин А.В. Галактоманнан семян гледичии китайской (Gleditsia sinensis Lam.). Прикладная биохимия и микробиология. 2010; 46:113-118 [Olennikov D.N., Rokhin A.V. Galactomannan seeds of Gleditsia chinese (Gleditsia sinensis Lam.). Applied biochemistry and Microbiology. 2010; 46:103-107]

9. Черепанов С.К. Сосудистые растения России и сопредельных государств (в пределах бывшего СССР). Русское издание. Санкт-Петербург: Мир и семья, 1995. 992 с. [Cherepanov S.K. Vascular plants of Russia and neighboring countries (within the former USSR). Russian edition. Saint-Petersburg: Mir i sem'ya; 1995.992 p. (in Russ.)]

10. Ahn D.K. Illustrated Book of Korean Medicinal Herbs. Kyohaku: Publishing Press, 2003. 628 p.

11. Artaud J., Iatrides M.C., Gaydou E.M. Bisdesmosidic saponins from fruits of Gleditsia caspica Desf. Revista Latinoamericana de Quimica. 1984; 37:218-229.

12. Cerqueira M.A., Souza B.W.S., Martins J.T., Teixeira J.A., Vicente A.A. Galactomannan from Gleditsia macracantha seeds and its biological activity // Chemistry of Natural Compounds. 2010; 41(1):10-11. DOI: $10.1007 / \mathrm{s} 10600-005-0062-6$

13. Chao L., Hui S., Wei-Ting W., Jin-Bao Z., An-Wei C., $\mathrm{Xu}$ G. A new triterpenoid saponin from Gleditsia sinensis and its antiproliferative activity. Journal Natural Product Research Formerly Natural Product Letters. $\quad 2016 ; \quad 30(18): 2065-2070 . \quad$ DOI: 10.1080/14786419.2015.1110704

14. Cheung C., Chui C., Cheuk O., Ngo T., Yi L., Cheng G., Wong R., Leung T. et al. Gleditsia sinensis fruit extract is a potential chemotherapeutic agent in chronic and acute myelogenous leukemia. Oncol. Rep. 2003; 10(5):1601-1607. DOI: 10.3892/or.10.5.1601

15. Chinese Pharmacopoeia Commission. Pharmacopoeia of the People's Republic of China. Chemical Industry Press, 2011. 3382 p.

16. Chow L, Tang J, Teo I., Chui C., Lau F., Leung T., Cheng G., Wong R. et al. Antiproliferative activity of the extract of Gleditsia sinensis fruit on human solid tumour cell lineschemotherapy. Experimental Chemotherapy. 2002; 48(6):303-308. DOI: $10.1159 / 000069713$

17. Dai Y., Chan Y., Chu L., But P. Antiallergic and antiinflammatory properties of the ethanolic extract from Gleditsia sinensis. Biol. Pharm. Bull. 2002; 25(9):11791182. 
18. Diego A., Alberto S., Carlos A. NMR spectroscopy and chemical studies of an arabinan-rich system from the endosperm of the seed of Gleditsia triacanthos. Carbohydrate Research. 2002; 337(3):255-263. DOI: 10.1016/S0008-6215(01)00310-X

19. Duchenko M.A. Research of polysaccharides compounds of Gleditsia triacanthos leaves. Украӥнський біофармацевтичний журнал (Ukrainian biopharmaceutical journal). 2014; 3-32):64-66.

20. Duchenko M.A., Demeshko O.V., Kovalev V.N. Flavonoids from Gleditsia triacanthos. Chemistry of Natural Compounds November. 2016; 52(6):1093-1094. DOI: $10.1007 / \mathrm{s} 10600-016-1870-6$

21. Duchenko M.A., Demeshko O.V., Kovalyov S.V., Kovalyov V.M. The amino acid and mineral composition of leaves and leaf fruit of Gleditsia. Вісник фармації (News of Pharmacy). 2010; 2(62):42-45.

22. Duke J.A., Wain D.D. Medicinal plants of the world plants. Beltsville: Genetics and Germplasm Institute, 1981. 520 p.

23. Egorov A.V., Mestechkina N.M., Shcherbukhin V.D. Determination of the primary and fine structures of a galactomannan from the seed of Gleditsia triacanthos f. inermis L. Applied Biochemistry and Microbiology. 2003; 39(4):398-402. DOI: 10.1023/A:1024524719296

24. Egorov A.V., Mestechkina N.M., Shcherbukhin V.D. Composition and structure of galactomannan from the seed of Gleditsia ferox Desf. Applied Biochemistry and Microbiology. 2004; 40(3):314-318. DOI: 10.1023/B:ABIM.0000025959.89870.c7

25. Ehab A.R. New antimicrobial and cytotoxic acylated triterpenoidal saponins from Gleditsia aquatic. Medicinal Chemistry Research. 2015; 24(7):2916-2925. DOI: $10.1007 / \mathrm{s} 00044-015-1345-5$

26. El-Sayed M.M., El-Nahas H.A., Abdel-Hameed E.S., El-Wakil E.A. Investigation and antioxidant of phenolic compounds of the leaves of Gleditsia triacanthos L. International fournal of Pharmacy and Pharmaceutical Sciences. 2013; 5(S2):172-177.

27. Harauchi Y., Kajimoto T., Ohta E., Kawachi H., Jinda A.I., Ohta S. Prenylated purine alkaloids from seeds of Gleditsia japonica. Phytochemistry. 2017; 143:145-150. DOI: 10.1016/j.phytochem.2017.08.006

28. Jiang J.-X., Jian H.-L., Zhang W.-M., Sun R.-C., Cristhian C. Structural and thermal characterization of galactomannans from genus Gleditsia seeds as potential food gum substitutes. Fournal of the Science of Food and Agriculture. 2011; 91(4):732-737. DOI: $10.1002 /$ jsfa. 4243

29. Jiangsu New Medical College. Dictionary Traditional Drugs. Shanghai: Shanghai Science \& Technology Press, 1979. $1431 \mathrm{p}$.

30. Jian-Ping Z., Xin-Hui T., Yong-Xun Y., Qing-Xin L., Qun W., Li-Ping C., Hui-Liang L., Wei-Dong Z. Gleditsia species: an ethnomedical, phytochemical and pharmacological review. Journal of Ethnopharmacology. 2016; 178:155-171. DOI: 10.1016/j.je 2015.11.044

31. Jinqian Y., Yan M., Gang L., Honglei Z. Anti-breast cancer triterpenoid saponins from the thorns of Gleditsia sinensis. Natural Product Research. 2018; 33(16):1-6. DOI: 10.1080/14786419.2018.1443092
32. Li W.H., Zhang X.M., Tian R.R., Zheng Y.T., Zhao W.M., Qiu M.H. A new anti-HIV lupine acid from Gleditsia sinensis Lam. Fournal of Asian Natural Products Research. 2007; 9(6):551-555. DOI: $\underline{10.1080 / 10286020600883419}$

33. Ligang Z., Duan L., Jingguo W., Yuanshuai L., Jianyong W. Antibacterial phenolic compounds from the spines of Gleditsia sinensis Lam. Nat Prod Res. 2007; 21(4):283-291. DOI: 10.1080/14786410701192637

34. Ligang Z., Duan L., Weibo J., Zhizhong Q., Shuang Z., Minghua Q. Two ellagic acid glycosides from Gleditsia sinensis Lam. with antifungal activity on Magnaporthe grisea. Nat Prod Res. 2007; 21(4):303309. DOI: $10.1080 / 14786410701192702$

35. Lim J.C., Park J.H., Budesinsky M., Kasal A., Han Y.H., Koo B.S., Lee S.I., Lee D.U. Antimutagenic constituents from the thorns of Gleditsia sinensis. Chem Pharm Bull (Tokyo). 2005; 53(5):561-564. DOI: $\underline{10.1248 / \mathrm{cpb} .53 .561}$

36. Liu Y., Xu Z., Zhang W., Duan J., Jiang J., Sun D. Characterization of fractional polysaccharides from Gleditsia sinensis and Gleditsia microphylla gums. Molecules. 2016; 21(12).pii: E1745. DOI: 10.3390/molecules21121745

37. Lozano F. Basic Theories of Traditional Chinese Medicine. In: Lin Y.-C., Hsu E. S.-Z. Acupuncture for Pain Management. New York: Springer, 2014. P. 13-43. DOI: $\underline{10.1007 / 978-1-4614-5275-12}$

38. Miguel A., Bartolomeu W.S., Souza J., Martins J.A., Teixeira A.A. Seed extracts of Gleditsia triacanthos: functional properties evaluation and incorporation into galactomannan films. Food Res. Int. 2010; 43(8):2031-2038.

39. Miyase T., Melek F.R., Warashina T., Selim M.A., El Fiki N.M., Kassem I.A. Cytotoxic triterpenoid saponins acylated with monoterpenic acids from fruits of Gleditsia caspica desf. Phytochemistry. 2010; 71(16):1908-1916 DOI: 10.1016/j.phytochem.2010.08.001

40. Miyase T., Melek F.R., Warashina T., Selim M.A., Kassem I.A.A. Bisdesmosidic saponins from fruits of Gleditsia caspica desf. Rev. Latinoamer. Quím. 2009; 37(3):218-229.

41. Mohammed R.S., Abou Z., El H. Sleem A.A., Ashou W.E. Flavonoid constituents, cytotoxic and antioxidant activities of Gleditsia triacanthos L. leaves Saudi J Biol Sci. 2014; 21(6):547-553. DOI: $10.1016 /$ j.sjbs.2014.02.002

42. Ragab E.A., Hosny M., Kadry H.A., Ammar H.A. Flavanone glycosides from Gleditsia caspia. Journal of Natural Products (Indian). 2010; 3:35-46.

43. Rakhmanberdyeva R.K., Kristallovich E.L., Rakhimov D.A., Mirzaeva M.R., Shtonda N.I. Watersoluble polysaccharides of seeds of the genus Gleditsia. Chemistry of Natural Compounds. 1998; 34(6):653-655. DOI: 10.1007/BF02336086

44. Rakhmanberdyeva R.K., Rakhimov D.A., Mirzaeva M.R. Galactomannan from Gleditsia texana seeds. Chemistry of Natural Compounds. 1999; 35(5):580-581.

45. Rakhmanberdyeva R.K., Rakhimov D.A., Mirzaeva M.R. Structure of galactomannan from seeds of Gleditsia macracantha. Chemistry of Natural Compounds. 1999; 35(5):505-507. 
46. Rakhmanberdyeva R.K., Rakhimov D.A., Vakhabov A.A., Khushbaktova Z.A., Syrov V.N. A new triterpenoid saponin GS-C' from Gleditsia delavayi. Acta Metallurgica Sinica. 2005; 24:1-3.

47. Rakhmanberdyeva R.K., Rakhimov D.A., Vakhabov A.A., Khushbaktova Z.A., Syrov V.N. Galactomannan from Gleditsia macracantha seeds and its biological activity. Chemistry of Natural Compounds. 2005; 41(1):11-13. DOI: 10.1007/s10600-005$\underline{0062-6}$

48. Rakhmanberdyeva R.K., Talipova M., Gazizov F., Rakhimov D.A. Carbohydrates and lipids of Gleditsia triacanthos seeds. Chemistry of Natural Compounds. 2002; 38(1):24-26. DOI.org/10.1023/A:1015717328738

49. Saleh D.O., Kassem I., Melek F.R. Analgesic activity of Gleditsia triacanthos methanolic fruit extract and its saponin-containing fraction. Pharm Biol. 2016; 54(4):576-580. DOI: 10.3109/13880209.2015.1064450

50. Santamour F.S. Flavonoid distribution in Gleditsia. Journal of Arboriculture. 1977; 3:14-18.

51. Sciarini L.S., Maldonado F., Ribotta D., Pérez G.T., León A.E. Chemical composition and functional properties of Gleditsia triacanthos gum. Food Hydrocolloids. 2009; 32(1):306-313.

DOI: 10.1016/i.foodhyd.2008.02.011

52. Seiler J., Jensen E., Niemiera A., Peterson J. Honey locust (Gleditsia triacanthos L.). Virginia Tech: Department of forest resources and environmental conservation, 2011. URL: http: dendro.cnre.vt.edu

53. Shcherbukhin V.D., Mestechkina N.M., Smirnova N.I., Anulov O.V. Galactomannan from the honey locust (Gleditsia triacanthos L.) introduced into Russia. Applied Biochemistry and Microbiology. 1997; 33(2):187-190.

54. Tahia K.M., Amel M.K., Mahmoud I.N., Maha A.E.A., Maha G.H., Heba A.M.E. Phenolic contents of Gleditsia triacanthos leaves and evaluation of its analgesic, anti-inflammatory, hepatoprotective and antimicrobial activities. Life Science fournal. 2013; 10(4):3445-3466.

55. Teng R.W., Ni W., Ding J.K., Wang D.Z., Chen C.X. Cooccurrence of $\Delta^{5}$ and $\Delta^{7}$ sterols in two Gleditsia species. A reassessment of the sterol composition in oils rich in d'sterols. Phytochemistry. 2002; 23:2303-2306.

56. Cerqueira M.A., Souza B., Martins J.T.; Teixeira J.A., Vicente A.A. Functional properties of Gleditsia triacanthos seeds extracts and their incorporation into galactomannan films for food applications. In: Waldron K.W.; Moates G.K.; Faulds C.B. Total Food: Sustainability of the Agri-Food Chain. London: Royal Society of Chemistry, 2010. 238-243. DOI: 10.1039/9781849730785

57. Wang Z., Ji Z., Jiang M., Ding X., Lu A., Shen C. Suggestion on publication and process norms of TCM clinical single case. 7 Beijing Univ Tradit Chin Med. 2009; 32:797-799.

58. Wan-Hua L., Xiang-Ming Z., Rong-Ren T., YongTang Z., Wen-Ming Z., Ming-Hua Q. A new anti-HIV lupane acid from Gleditsia sinensis Lam. I Asian Nat Prod Res. 2007; 9(6-8):551-555.

DOI: $10.1080 / 10286020600883419$

59. Wilson A. Honey locust agroforestry. Virginia University, 2006. URL: http: faculty.virginia.edu

60. Wu J., Li J., Zhu Z., Huang G., Tang Y., Gao X. Protective effects of echinocystic acid isolated from Gleditsia sinensis Lam. against acute myocardial ischemia. Fitoterapia. 2010; 81(1):8-10. DOI: 10.1016/j.fitote.2009.06.015

61. Zhang C.R., Dissanayake A.A., Nair M.G. Functional food property of honey locust (Gleditsia triacanthos) flowers. Fournal of Functional Foods. 2015; 18(A):266274. DOI: $10.1016 /$ j.jff.2015.07012

62. Zhang Z., Koike K., Jia Z., Nikaido T., Guo D., Zheng J. Triterpenoidal saponins from Gleditsia sinensis. Phytochemistry. 1999; 52(4):715-722. DOI: 10.1016/s0031-9422(99)00238-1

63. Zhou L., Li D., Wang J., Liu Y., Wu J. Antibacterial phenolic compounds from the spines of Gleditsia sinensis Lam. Nat Prod Res. 2007; 21(4):283-291. DOI: $10.1080 / 14786410701192637$

Для цитирования: Сальникова Н.А., Самотруева М.А., Коновалов Д.А. Химический состав и фармакологические свойства растений рода Gleditsia L. (обзор литературы). Курский научно-практический вестник «Человек и его здоровье». 2019; (3):87-96. DOI: $10.21626 /$ vestnik/2019-3/12. 


\title{
THE CHEMICAL COMPOSITION AND PHARMACOLOGICAL PROPERTIES OF PLANTS OF GLEDITSIA L. (LITERATURE REVIEW)
}

\author{
○ Salnikova N.A. ${ }^{1}$, Samotruyeva M.A. ${ }^{1}$, Konovalov D.A. ${ }^{2}$ \\ ${ }^{1}$ Astrakhan State Medical University (ASMU) \\ 121, Bakinskaya St., Astrakhan, Astrakhan region, 414000, Russian Federation \\ ${ }^{2}$ Pyatigorsk Medico-Pharmaceutical Institute (PMPI) \\ 11, Kalinin Ave., Pyatigorsk, Stavropol Krai, 357532, Russian Federation
}

\begin{abstract}
The article analyzes the world scientific literature concerning the study of types of Gleditsia L. (Gledichiya), growing almost on all continents, but the special attention is drawn to the types of Gleditsia caspia Desf. and Gleditsia tricanthos L. as main representatives of North American flora in Russian Federation. Different morphological parts of Gleditsia L. contain the rich chemical composition which ratio depends on a plant species. In raw materials of G. sinensis phenolic compounds and phenolic acids, flavonoids, lupic acid, echinocystic acid, and triterpene saponins are found. G. caspica contains triterpene saponins, monoterpenic acids and sterols, bisdesmosidic saponins, flavonons. In G. delavayi triterpene saponins are found. Galactomannans are found in beans of G. macracantha and G. triacanthos. In raw materials of G. triacanthos 8 flavonoids, including 6 flavonoid glycosides are found: vicenin -II, lucenin, isoorientin, orientin, vitexin, isovitexin along with two aglycones, namely luteolin and apigenin. The wide range of pharmacological action of the sort Gleditsia L. is confirmed by longterm experience of Chinese and Korean traditional medicine, indigenous people of North America and modern scientific data. Different authors under the conditions in vitro for the raw materials of Gleditsia L. confirmed spasmolytic and cytotoxic activity, anti-inflammatory, anti-mutagen and antimicrobic action.
\end{abstract}

Keywords: Gleditsia L.; flavonoids; triterpene saponins; galactomannan; pharmacological properties.

Salnikova Natalya A. - PhD in Biology, Associate Professor, Associate Professor of Department of Pharmacognosy, Pharmaceutical Technology and Biotechnology, ASMU, Astrakhan, Russian Federation. ORCID iD: 0000-0003-2783-4059. E-mail: natalya-salnikova-81@mail.ru (correspondence author)

Samotruyeva Marina A. - DM, Associate Professor, Head of Department of Pharmacognosy, Pharmaceutical Technology and Biotechnology, ASMU, Astrakhan, Russian Federation. ORCD iD: 0000-0001-5336-4455. E-mail: ms1506@mail.ru

Konovalov Dmitry A. - Doctor of Pharmacy, Professor, Head of Department of Pharmacognosy, Botany and Technology of phytopreparations, PMPI, Pyatigorsk, Russian Federation. ORCID iD: 0000-0002-0960-6127. E-mail: D.A.Konovalov@Pmedpharm.Ru

\section{CONFLICT OF INTEREST}

The authors declare the absence of obvious and potential conflicts of interest related to the publication of this article.

\section{SOURCE OF FINANCING}

The authors state that there is no funding for the study.

For citation: Salnikova N.A., Samotruyeva M.A., Konovalov D.A. The chemical composition and pharmacological properties of plants of Gleditsia 1. (literature review). Kursk Scientific and Practical Bulletin "Man and His Health". 2019; (3):87-96. DOI: 10.21626/vestnik/2019-3/12. 